\title{
PROTECTING UNESCO WORLD HERITAGE PROPERTIES'S INTEGRITY: THE ROLE OF RECORDING AND DOCUMENTATION IN RISK MANAGEMENT FOR PETRA
}

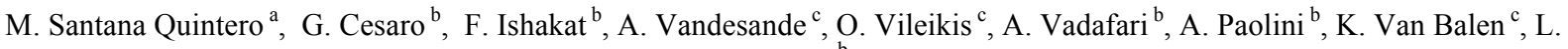 \\ Fakhoury ${ }^{\text {, }}$ \\ ${ }^{a}$ Carleton University, Civil and Environmental Engineering, Ottawa, ON, K1S 5B6, Canada, \\ mario_santana@carleton.ca \\ ${ }^{\mathrm{b}}$ UNESCO Amman, Culture Unit, Amman, Jordan \\ ${ }^{c}$ Raymond Lemaire International Centre for Conservation (RLICC), KULeuven, Heverlee, Belgium
}

Working Group V/2; Cultural Heritage Data Acquisition and Processing

KEY WORDS: conservation, preventive maintenance, recording, risk assessment, threats, cultural heritage.

\begin{abstract}
:
Risk management - as it has been defined - involves the decision-making process following a risk assessment (Ball, Watt, 2003). It is the process that involves managing to minimize losses and impacts on the significant of historic structures and to reach the balance between gaining and losing opportunities. This contribution explains the "heritage information" platform developed using low-cost recording, documentation and information management tools to serve as container for assessments resulting from the application of a risk methodology at a pilot area of the Petra Archaeological Park, in particular those that permit digitally and cost effective to prepare an adequate baseline record to identify disturbances and threats. Furthermore, this paper will reflect on the issue of mapping the World Heritage property's boundaries by illustrating a methodology developed during the project and further research to overcome the lack of boundaries and buffer zone for the protection of the Petra World Heritage site, as identified in this project.
\end{abstract}

This paper is based on on-going field project from a multidisciplinary team of experts from the Raymond Lemaire International Centre for Conservation (University of Leuven), UNESCO Amman, Petra Development Tourism and Region Authority (PDTRA), and Jordan's Department of Antiquities (DoA), as well as, experts from Jordan. The recording and documentation approach included in this contribution is part of an on-going effort to develop a methodology for mitigating (active and preventive) risks on the Petra Archaeological Park (Jordan). The risk assessment has been performed using non-intrusive techniques, which involve simple global navigation satellite system (GNSS), photography, and structured visual inspection, as well as, a heritage information framework based on Geographic Information Systems. The approach takes into consideration the comparison of vulnerability to sites with the value assessment to prioritize monuments at risk based on their importance of significance and magnitude of risk, in order for the authorities to plan more in-depth assessment for those highly significant monuments or areas at risk. A decision tool is envisaged as outcome of this project.

\section{INTRODUCTION}

\subsection{Framework}

The Raymond Lemaire International Centre for Conservation at the KU Leuven has been involved since 2010 in a major UNESCO initiative in Jordan, dealing with the risk assessment of world heritage properties. This contribution stresses the need of a systematic approach for the detection of change that affects continuously and eventually drastic the fabric of these important heritage places. The present contribution will focus on Petra, which is presented at the property/area level and deals with the visual inspection of disturbances and threats to specific areas of the site.

According to Clark, "Understanding the physical fabric of a site is an important first step in finding the right conservation strategy, and documentation is the first step in understanding." Documentation can serve multiple challenges in the study and protection of cultural heritage, such as the creation of a permanent record, which is passed on from generation to generation and can be available in case of destruction and/or alterations in the heritage's significance and integrity.
In the case of this particular project, the documentation approach has utilized rapid-assessment techniques based on forms, georeferenced photographs, GNSS, and GIS.

As mentioned previously, these tools can effectively serve to produce an appropriate level of detail for the "base line record" to identify current/potential changes over time that potentially threat the heritage integrity addressed by the "Outstanding Universal Criteria(s)" for which this important site has been recognize by UNESCO's World Heritage Committee. 


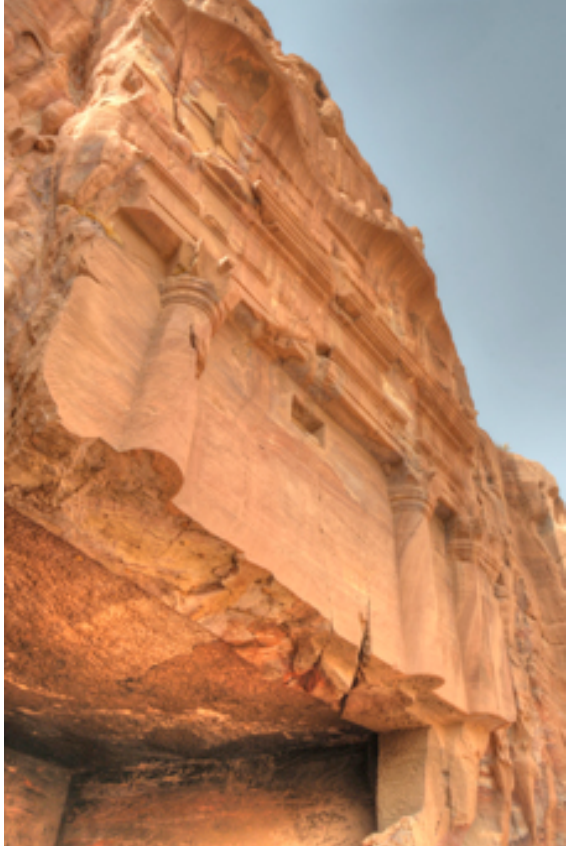

Figure 1: Turkmaniyya tomb, Petra.

The Risk assessment method provides a tool for prepared to help site managers to prevent, reduce and actively act on the negative impacts resulting from on-going disturbances/ threats on the significance/integrity of the property and on human life. It deals with major threats, like earthquakes, but also with factors increasing the vulnerability to risks. Minor factors, which can become preponderant with time because of their cumulative effects, are also considered: lack of maintenance, inadequate management, progressive erosion and deterioration.

\subsection{Heritage information in Jordan}

The heritage information strategy for systematic identification and documentation of heritage places in Jordan has been only partially acquired. An IT inventory of archaeological sites in Jordan JADIS (Jordan Antiquities Database and Information System - a programme created by ACOR under a grant of USAID in the nineties), this system is still nowadays the most comprehensive database for sites in Jordan.. Since 2009, most of the JADIS sites have been transferred to the Middle Eastern Geodatabase for Antiquities (MEGA-J), which is a joint effort by the Getty Conservation Institute, the World Monuments Fund and the Department of Antiquities of Jordan.

All archaeological sites in the country are now recorded in this Google-based, web-accessible GIS. However, data enter for the World Heritage property of Petra has not been carried out completely yet by the Department of Antiquities. At present, 149 sites, approximately corresponding to all those already recorded in JADIS, have been transferred into MEGA-J for the Petra region. However, monuments located in the city centre still appear as clusters under the generic name of 'Petra' with no reliable coordinates measured with GPS, nor a plan attached to them. There is therefore a strong need to update the system so that all information on the most relevant monuments can be properly recorded and shared among professionals in the heritage field.

The need of an adequate "heritage information" policy and adequate cartography/reference map is one of the major gaps identified in Petra. This also poses indirect threats to the park.
Lack of information equals lack of protection because no knowledge is shared on what has to be protected.

\section{DESIGNING A RISK MANAGEMENT METHODOLOGY}

The issue of risk assessment has been extensively investigated in recent years; however it has been mostly applied for the prevention of drastic and sudden events affecting cultural heritage resources. In this contribution, risk assessment is considered as an important activity in any decision making for the management of properties tackling both drastic and continuous risks. For this reason a panel of experts have been set up to review the progress of the risk methodology development, especially in the case of Petra.

The suggested methodology, currently in development, is centralized in issues affecting the integrity of the cultural significance of a building and its surfaces as the basis for good risk estimation. Extensive research has been carried out at this heritage property, but very little effort has been concentrated in evaluating the values and how they can be affected by a rate of deterioration, continuous and/or drastic.

Risk management -as it has been defined- involves the decision-making process following a risk assessment (Ball, watt, 2003). It is the process that involves managing to minimize losses and impacts on the significant of historic structures and to reach the balance between gaining and losing opportunities.

This proposal intended to provide guidance and methodology for the establishment and implementation of such risk management plan at UNESCO World Heritage Properties. The risk assessment in complement with the value assessment will provide a tool to prioritize monuments at risk based on their importance of significant and magnitude of risk, in order for the authorities to plan more in-depth assessment for those highly significant monuments or areas at risk. Based on this prioritizing, decisions could be made on appropriate mitigation strategies. Hence a risk management plan can provide a decision making tool for the preventive conservation of the property.

Planning is the key element for the decision-making. As noted in Planning for Conservation and Management of Archaeological Sites, the protection and conservation of heritage places for future generations involves "Good" decisions as the result of careful planning (Demas, 2003), which allows demising and slowing the impact of change that might affect the significance and integrity of the fabric and therefore the experience of visitors at heritage properties and more specifically at the Petra Archaeological Park.

A planning process helps to sort through multi layer and complex issues facing heritage sites, set priorities, explain and justify decisions and ensure that the result of decisions are sustainable.

Risk management in Petra consists of different steps of planning: establish context and scope, identifying, analysing, assessing, evaluating, mitigating, and monitoring; which when undertaken in sequence will facilitate and improve the decisionmaking and its sustainability. 


\subsection{Pilot area}

Selected and representative site elements were selected in a pilot area of the Petra Archaeological Park within the recognized UNESCO World Heritage 1993 property boundaries. The Pilot Area for the rapid risk assessment fieldwork consists of the followings:

The Temple of Winged Lions that includes standing structures and "disturbances" related to impact of visitors, researchers and contractors..

The Basin, it is characterized by the concentration of visitors facilities, car parks for "authorized vehicles", animals resting and waiting area, significant archaeological elements are not present in the area but because of its topography (wadis and cliffs) it is an area that would help to understand the landscape and the relationship that exists between landscape and monuments. Also, this area is representative of tourism concessioner activities and other human behavioural impacts on the landscape and surrounding elements. areaThe Turkmaniyya Tomb area included carved structures located near the road, representative of a threat, and future impacts derived by the construction of a wider road to provide an exit road to Petra.

The substantial difference between the components of the Pilot area can be observed at several levels from their intrinsic properties up to their historical and present significance. Given this distinct difference between the noted components, it was necessary to conduct a thorough comparison concerning the methodological approach for each step of the assessment; as well as, to adapt the "heritage information" strategy. For this reason, a simple GIS platform was designed.

\subsection{Application of recording tools}

The assessment teams were equipped with a handheld GPSdevice GeoXH 2008, using DGPS with SBAS (EGNOS)corrections (on WGS84 coordinates), which allowed controlling the precision directly on the field by means of measurements with accuracy under $1 \mathrm{~m}$, as well as, enhancing portability and lower cost than using a differential GPS device.

Furthermore, the team used both digital photography to capture disturbances and threats as well as spherical panoramic photography, which was georeferenced using the Hand held GPS.

Monuments with their location and information were recorded in the MEGA-J system. Six threats and Disturbances categories of MEGA-J were used for identifying and recording condition and risk namely: agricultural, development, human, natural, site management, and other impacts. Threats and disturbance identification was done based on visual inspection.

Identification of agents and causes of deterioration (or possible future deterioration) and threats was the next step in the recording of risks before assessing the level of threat (risk assessment).

\subsection{Processing information collected: building a relevant Geographic Information System for risk assessment}

The risk methodology results and the visualization of the multilayered assessment approach required for the pilot area studied were greatly enhanced by a GIS. The GIS project can easily query for patterns, identify concentration and visualize congestion areas, where different risk indicators overlap in a pilot area. Once the risks, their subsequent information and their impact area are inserted in the GIS database, fast queries can be conducted according to the defined attributes.

Given that the GIS project generates the possibility to manage and deduce detailed information from a site element, it is appropriate to integrate other site elements of the pilot area. It was opted to include the Temple of the Winged Lions in this preliminary risk assessment GIS project.

\section{BOUNDARY MAPPING}

Despite the status of Petra as one of the most famous World Heritage sites in the world thanks to its peculiar architecture including structures half built and half-carved into the rock and its nomination as one of the Seven Wonders in 2007, the site is nowadays threatened by risks of different kinds and not surprisingly appeared also in the list of the most endangered sites in the world for four consecutive years $(1996,1998,2000$ and 2002).

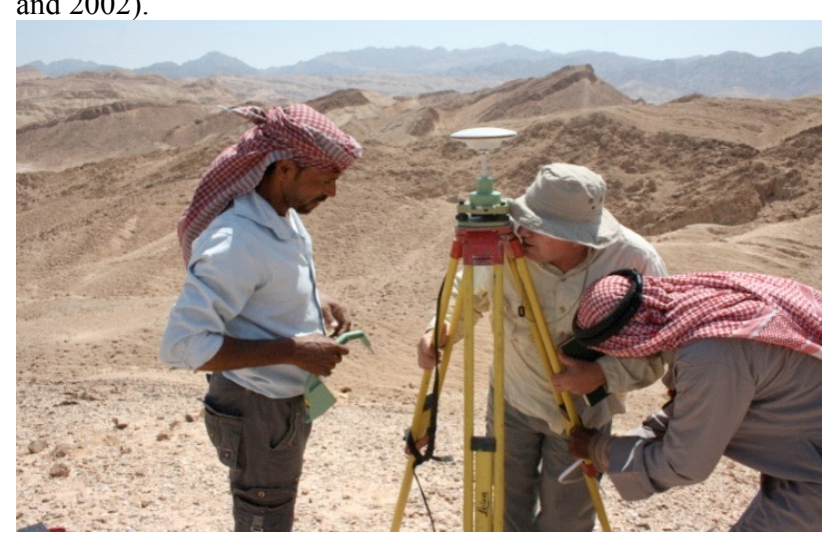

Figure 2: mapping the boundaries using a base station to enhance accuracy.

In addition, its early nomination accounts for the inaccuracy in the definition of the boundaries of the property, of which no identification on the ground was ever carried out (until very recently) and the lack in the definition of its buffer zone. In relation to this, to date the site still lacks a comprehensive base map to be used as a reference for all management, touristic and conservation activities undertaken on site, while the lack of well defined boundaries represents a major threat to site integrity.

This -section of the paper deals with the description of the surveying of the existing PAP boundaries to examine their effective protection to the current Petra Archaeological Park and how a possible $10 \%$ extension to the World Heritage property's boundaries together with a well articulated proposal for a buffer zone could allow for a better preservation of the site's integrity and authenticity and could contribute to the better management and effective protection of the Petra Archaeological Park.

The project tackled the following ideas: 
The correct definition of boundaries would ensure better protection and management of the park. The area would be managed in its complete extension rather than being accounted for the sole city centre;

Definition of boundaries will ensure better protection to the park and reduce risks derived from external agents;

- Definition of boundaries will eventually solve the base map problem, as one requirement for boundaries is to rely on reliable geographical documentation.

The present part articulates in the preparation of this boundary accurate mapping and the proposals for increasing the $10 \%$ boundary.

\subsection{Application of recording tools}

Petra Archaeological Park spreads over 264 square kilometres, with different levels of difficulty in terms of accessibility.

A fieldwork was started in April 2011 based on documents provided by the Petra Development \& Tourism Regional Authority (PDTRA) including GIS data and JTM coordinates of the PAP boundary points. Using Arc Map 10, JTM coordinates of the PAP points were transformed into UTM, the resulting digital layer file represented the outline of the park as defined in 1993.

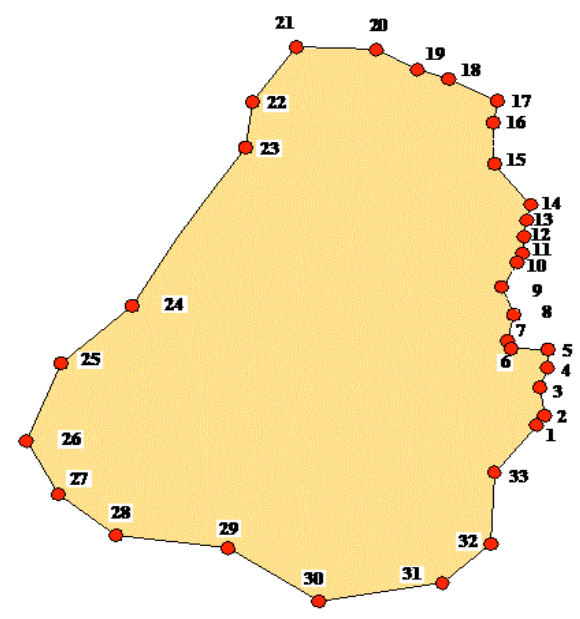

Figure 3: original boundary coordinates provided by the PDTRA.

These measurements were then transferred to a handheld GPSdevice GeoXH 2008, using DGPS with SBAS (EGNOS)corrections (on WGS84 coordinates), which allowed controlling the precision directly on the field with measurements with accuracy under the $1 \mathrm{~m}$, as described before.

In order to make the fieldwork more effective and more organized, we divided the Petra Archaeological Park into different areas (Figure 7) and each coordinate point from the original file was identified in the ground. Once mapped, the points were physically marked on the ground with an iron stake stabilized with concrete; and the point number written on top of the mark.

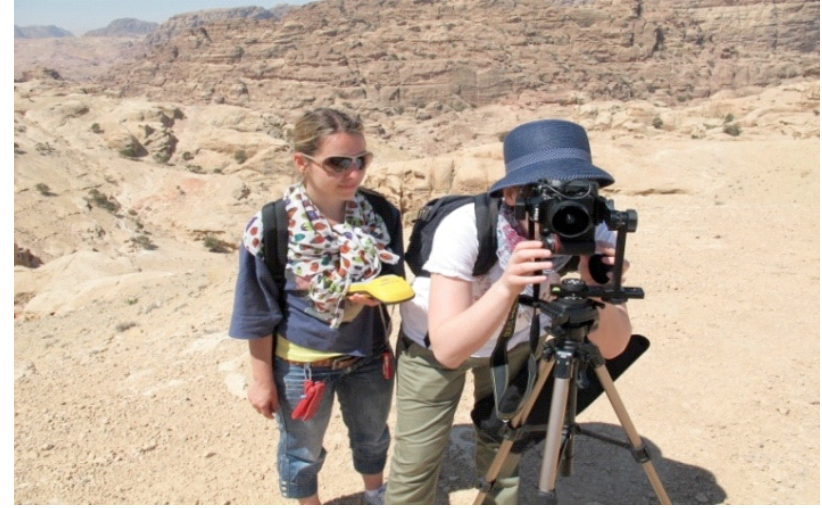

Figure 4: georeferenced photography to record the boundary points.

Furthermore, a set of three photographs was taken, one looking intra boundary, one extra boundary, as well as, one looking at the materialized point. These photographs were georeferenced and stored in the GIS database along with the boundary points.

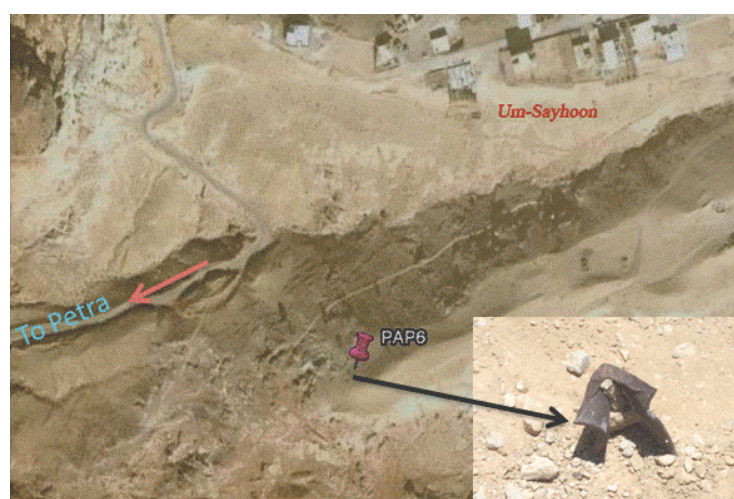

Figure 5: materialized point illustrated with a georeferenced photograph.

\subsection{Other information collected: georeferenced photographs}

The GPS measurements and photographs taken were integrated into a GIS system and the resulting files were transmitted to the local authorities. The mapped points will be materialized using more solid construction materials in agreement with the Jordan Department of land and Survey, giving this project validation and an important contribution to the protection of Petra. 


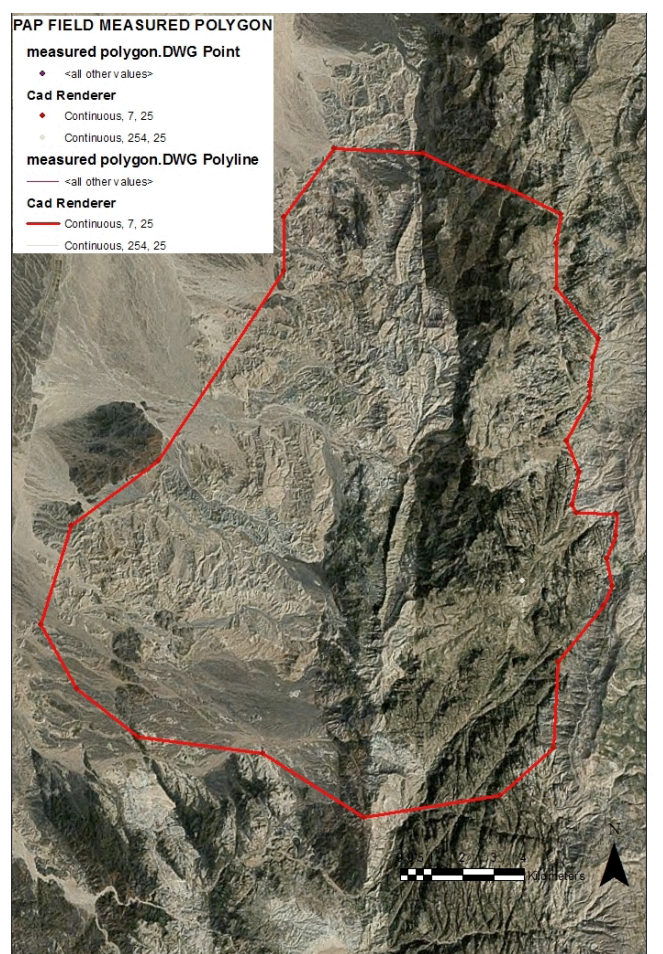

Figure 6: resulting polygon after mapping with the GPS.

\subsection{Developing an approach}

The identification and mapping of significant number of points required more time than expected, because of the roughness and rigidity of terrain. Even four-wheel drive car was sometimes not able to reach areas in the western sector of Wadi Araba, and in many cases the recording team had to leave the car and basically walk to reach the point. This all affected in slowing the whole measuring process.

\subsection{Analysing the boundaries and making proposals}

Based on the boundary mapping, a systematic methodology of "area analysis" was carried out. This study was essential to understand the current boundaries and whether they satisfy the requirements for which they had been established.

Conducting an analysis at the area level can be the first step towards an area evaluation, then leading to a more articulated proposal for all PAP areas.

It is therefore worth having a better general understanding of the Petra Archaeological Park extended area and surrounding boundaries before entering a more precise explanation at area and point level. Boundaries (and areas located in proximity to them), were analysed throughout a macro, meso \& micro level approach.

MACRO: at the macro level boundaries appear as a pear arbitrarily shaped polygon surrounded by the esh-Shera mountains. Six villages (Wadi Musa, Um Sayhun, Beidha, Taybeh, Rajif, Dlagha) inhabited by the local Bedouin communities are located along them on the east, although not included within the boundaries: most of them, except Wadi Musa and Beidha, are located on hill tops.

MESO: at the meso level boundaries could be divided into 9 sub-areas, which differ from one another for terrain, environment, proximity to urban areas, use by local communities, vegetation, etc.

$M I C R O$ : at the micro level each boundary point is taken into account separately.

Due to its extension and complexity, the study of the Petra Archaeological Park area has to start from the micro level. The context has to be perceived from its different points of view before going into a more detailed analysis. Once this has been done, it is possible to move back to the meso and macro levels for a conscious evaluation.

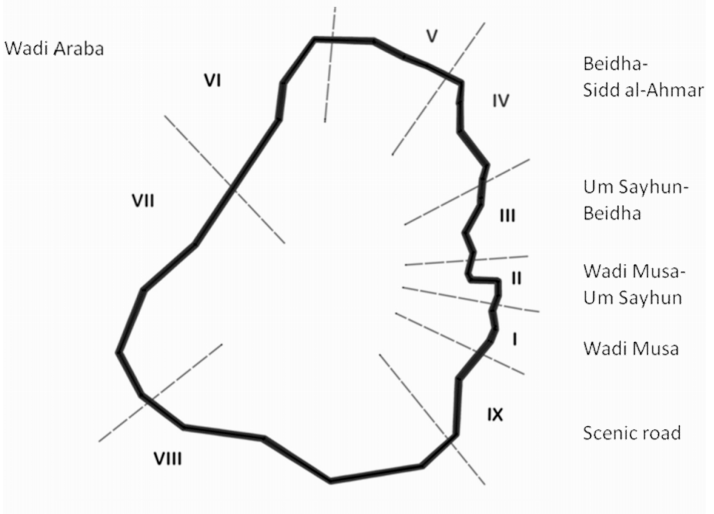

Masouda-Wadi Sabra
Figure 7: defined areas for boundary study.

This approach counted with a simple GIS platform to archive and manage geographic information, satellite images and georeferenced photographs illustrating the assessment of each of the areas studied leading to the boundary extension proposals. The outcome of this study is extensively presented in Cesaro's master thesis; the scope of this paper is limited to present the "heritage information" approach developed to carry out this study.

Each of the areas studied were evaluated assessing their characteristics (values) and the location of the boundary points and boundary line passing through them. The features/values that were taken into account area-by-area equal the values, and are namely:

- $\quad$ Cultural (archaeological)

- $\quad$ Natural (geology/hydrology/vegetation)

- $\quad$ Social (aspect \& use)

- Views

In order to have a better picture of the situation area by area, the values assessment also counted with evaluating the threats to each area.

The resulting assessment by Cesaro yielded three scenarios, considering one with more than $10 \%$ extension and two equal to $10 \%$ extension in different areas. Figure 8 illustrates one of the scenarios. 


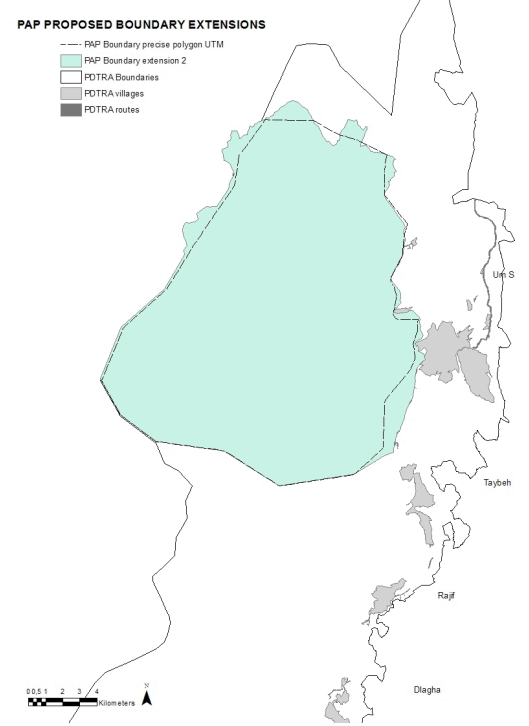

Figure 8: proposed scenario for an extension equal to $10 \%$ of the PAP.

\section{CLOSING REMARKS}

The "heritage information" strategy proposed for the rapidassessment applied on a "risk assessment methodology" has been cost effective and yielded the expected results.

However, in the future, it should be accompanied by good cartography of the property, including its boundaries, site elements, features and topography. This could enable to collect a considerable amount of well-structured information. Simultaneously, this process produces a ready-to-use tool for site managers (and researchers) for monitoring "change" and "impact" on the site and forecast mitigation strategies.

In terms of the boundary mapping, equally important the "heritage recording" approach developed has been cost effective and yield relevant results. This approach should be further developed for other World Heritage properties, as a good practice example of the way to analyse the importance of each area and its contribution to the global understanding of the Outstanding Universal Values of a site.

\section{REFERENCES}

Cesaro, G., "Boundaries and buffer zone as Tools for Protecting Integrity at World Heritage Properties: the case of Petra, Jordan", Master thesis at the Raymond Lemaire International Centre for Conservation, KU Leuven, 2011 (unpublished)

Demas, M. "Planning for Conservation and Management of Archaeological Sites: A Values-Based Approach" Teutonico, J. Palumbo, G. ed. Management planning for archaeological sites: an international workshop organized by the Getty Conservation Institute and Loyola Marymount University, 19-22 May 2000, Corinth, Greece. ix +158 pages, 59 figures, 3 tables. 2002. Los Angeles (CA): Getty Conservation Institute; 0-89236-691-5, Getty Conservation Institute

Getty Conservation Institute and World Monuments Fund 2010. Middle Eastern Geodatabase for Antiquities (MEGA) - Jordan: Guidelines for Completing Site Cards, unpublished document.

Getty Conservation Institute and World Monuments Fund Middle Eastern Geodatabase for Antiquities (MEGA), http://www.getty.edu/conservation/our_projects/field_projects/j ordan/ (12 April 2012)

Letellier, R. Schmid, W. LeBlanc, F. Guiding Principles Recording, Documentation, and Information Management for the Conservation of Heritage Places, Getty Conservation Institute, 2007 J. Paul Getty Trust, pp. 36-38.

Matero, Frank G. 2003. "Managing change: The role of documentation and condition survey at Mesa Verde national park", In Journal of the American Institute for Conservation (JAIC), 42, 39-58.

Santana Quintero, M., Smars, P., Patricio, T. (2011). Preparing a risk preparedness approach for Baalbek. In: Santana Quintero M., Seif A. (Eds.), Protecting BAALBEK's Integrity: A proposal for an integrated risk preparedness strategy (pp. 4453). Leuven, Belgium: . Raymond Lemaire International Centre for Conservation (KU Leuven) - University College St. Lieven.

UNESCO "The Operational Guidelines for the Implementation of the World Heritage Convention", Paris 2011, http://whc.unesco.org/en/guidelines (20 March 2012)

UNESCO The World Heritage Resource Manual: managing Disaster Risks for World Heritage, ICCROM, 2010.

Van Balen, K., 2008 The Nara Grid: An Evaluation Scheme Based on the Nara Document on Authenticity, The Association for Preservation Technology International (APT), Vol. 39, No. 2/3, pp. 39 .

\subsection{Acknowledgements}

The project members wish to acknowledge the support of UNESCO Amman and the Raymond Lemaire International Centre for Conservation (University of Leuven) for the opportunity to participate in this important project towards the protection of the Petra Archaeological Park.

We would also like to acknowledge and thank the continuous support of the Petra Development and Tourism Regional Authority (PDTRA) including the Petra Archaeological Park unit, and the Department of Antiquities of Jordan (DoA).

Furthermore, we would like to acknowledge the ultimate beneficiaries of this project: stakeholders and local authorities that have contributed extensively with the rate of success of this challenge. As well as, the national and international experts that have been involved in various meetings, workshops and field activities. Among those, we are particularly grateful to Dr. Emad Hijazeen, Eng. Tahani Al Salhi, Fawwaz Ishakat, Guido Kips, Talal Akasheh, Chris Tuttle, and Bilal Khreisat.

It is also important to remember the substantial contribution of the RLICC class of 2011 students, and the coordinative efforts of Luc Verpoest, Caressa Cornelis, Kristine Loonbeek. Special thanks to Malou Maes, Aziliz Vandesande, Razan Shadfan, Mohammad Bataineh and PAP and DoA staff for applying the risk management methodology in the pilot area of Petra.

Finally, we would like to thank all those individuals and institutions that in one way or another helped with the completion of this project. 